\title{
Enantiomeric Determination of Omeprazole and Esomeprazole by a Developed and Validated Chiral HPLC Method and Stability Studies by Microthermal Analysis
}

\author{
Asma Rahman ${ }^{1,2}$, Mohammad Rashedul Haque ${ }^{1}$, Md. Zakir Sultan², \\ M. Muhibur Rahman ${ }^{3}$ and Mohammad A. Rashid ${ }^{1}$ \\ ${ }^{1}$ Department of Pharmaceutical Chemistry, Faculty of Pharmacy, University of Dhaka, \\ Dhaka-1000, Bangladesh \\ ${ }^{2}$ Centre for Advanced Research in Sciences (CARS), University of Dhaka, Dhaka-1000, Bangladesh \\ ${ }^{3}$ Department of Chemistry, University of Dhaka, Dhaka 1000, Bangladesh
}

(Received: September 06, 2017; Accepted: November 28, 2017; Published (web): December 23, 2017)

\begin{abstract}
A rapid, accurate, precise, stability indicating and enantioselective chiral HPLC method was developed and validated for the quantitative $(S)$ - and $(R)$ - omeprazole in omeprazole formulations along with determination of enantiomeric purity of $(S)$ - omeprazole in esomeprazole formulations according to the guidelines of the United States of Pharmacopeia (USP) and International Conference on Harmonization (ICH). The chromatographic separation was achieved with $n$-hexane/ 2-propanol/ acetic acid/ triethylamine (100: $20: 0.2: 0.1$, $\mathrm{v} / \mathrm{v}$ ) at a flow rate of $1.2 \mathrm{ml} / \mathrm{min}$ on Chiralcel OD-H and detected at $300 \mathrm{~nm}$. The method showed good linearity, high sensitivity with detection limit (LOD) of 0.71 and $1.16 \mu \mathrm{g} / \mathrm{ml}$ and quantitation limit (LOQ) of 2.16 and 3.51 $\mu \mathrm{g} / \mathrm{ml}$ for $(S)$ - and $(R)$ - omeprazole, respectively. The average percentage of recovery was found to be $100.85 \%$ to $101.36 \%$ for $(S)$ - and $99.81 \%$ to $101.62 \%$ for $(R)$ - omeprazole. The average percentage of relative standard deviation (\% RSD) for intra- and inter- day precision were found to be $0.05 \%$ and $0.19 \%$ for $(S)$ - and $0.03 \%$ and $0.13 \%$ for $(R)$ - omeprazole, respectively. Stability study was performed under stress conditions. Microthermal analysis of omeprazole was also performed by thermogravimetric analysis (TGA), differential scanning calorimetry (DSC), and scanning electron microscopy (SEM) to assess the physical and chemical behavior of the drug. The method was successfully applied to the quantitation of $(S)$ - and $(R)$ - omeprazole for omeprazole and as well as determination of $(S)$ - omeprazole purity for esomeprazole formulations.
\end{abstract}

Key words: Omeprazole, enantiopurity, method development, validation, stability study.

\section{INTRODUCTION}

Omeprazole is the most popular proton-pump inhibitor (PPI) mainly used to reduce gastric acid secretion by targeting the gastric acid pump, $\mathrm{H}^{+}, \mathrm{K}^{+}$, adenosine triphosphatase (ATPase) in the canalicular membrane of parietal cell. ${ }^{1}$ It is also used to treat diseases like dyspepsia, gastroesophageal reflux disease (GERD), laryngopharyngeal reflux, and Zollinger-Ellison syndrome. ${ }^{2,3}$ Omeprazole, 6methoxy-2-[94-methoxy-3,5-dimethylpyridin-2-yl)

Correspondence to: Mohammad A. Rashid

E-mail: rashidma@du.ac.bd

Tel.: +88-02-9661900-73, Extn. - 8137. Fax: +88-02-9667222

Dhaka Univ. J. Pharm. Sci. 16(2): 221-233, 2017 (December) methanesulfinyl] $1 H$-1,3-benzodiazole possesses an asymmetric sulfoxide moiety exhibiting $(S)$ - and $(R)$ omeprazole as equimolar mixture (1:1) of the two 4,5 (Figure 1). (S)- omeprazole received approval with more pronounced inhibition of acid secretion and less inter-patient variation than omeprazole. ${ }^{6,7}$ Literature survey revealed that $(S)$ - omeprazole provides more effective acid control than twice the dose of omeprazole $^{8}$, as $(S)$ - omeprazole compared to omeprazole is metabolized more slowly in human liver by CYP 2 C19 and CYP 3 A4. ${ }^{9}$ For this, attention is now focused on the purity of active single enantiomers, $(S)$ - omeprazole marketed as esomeprazole. 
Similar physical and chemical properties of the two enantiomers make the separation very difficult. So, the development of a method for the quantitative analysis of chiral compounds is extremely challenging at present. ${ }^{10}$ According to the US Food and Drug Administration, a selective assay method should include the separation and determination of enantiomeric drugs. Therefore, analytical methods of chiral drugs are highly needed. ${ }^{11,12}$ Chiral techniques involve the use of gas chromatography (GC), supercritical fluid chromatography (SFC), capillary electrophoresis (CE), and high-performance liquid chromatography (HPLC). HPLC is most widely employed for its high sensitivity and efficiency for separation of enantiomers. ${ }^{13}$ Chiral stationary phase, CSP has been widely used in separation and determination of omeprazole and other PPI drugs. ${ }^{14-22}$ Chiralcel OD-H, Cellulose-tris-(3, 5-dimethylphenylcarbamate) (Figure 2) coated on silica-gel as CSP offered the highest enantiomeric separation. ${ }^{23,24}$ Determination of enantiomeric excess (ee) of chiral compounds is performed by chiral HPLC. ${ }^{25-28}$

For racemic omeprazole, a number of research papers were reported on development and validation of HPLC methods. Vyas et al. reported a method using Chiralcel OD-H to determine omeprazole enantiomers in commercial formulations. ${ }^{4}$ However in this method, resolution obtained of the two enantiomers $(S)$ - and $(R)$ - omeprazole was found to be $<2$ but according to USP guidelines it should be $\geq 2 .{ }^{29-31}$ Therefore, the objective of the present investigation was to develop a rapid and easy chiral HPLC method for simultaneous quantification of $(S)$ and $(R)$ - omeprazole in racemic omeprazole with improved resolution, and to validate the method according to USP, ICH guidelines. CSP, cellulosetris-(3,5-dimethylphenylcarbamate) (Figure 2) coated on silica-gel known to offer the highest enantiomeric separation ${ }^{12,13}$ was chosen as the stationary phase and the composition of the mobile phase and its flow rate were optimized. Forced degradation study was performed with this proposed method. In addition to these, physical and chemical properties of drug substances were also studied by microthermal analysis combined with TGA, DSC, and SEM as they are well-established techniques for characterizing the morphology and composition of components. ${ }^{32-34}$ Therefore, the present study covered the development of a improved chiral method, enough validation parameters, $\%$ purity of enantiomers, and degradation study along with microthermal analysis.

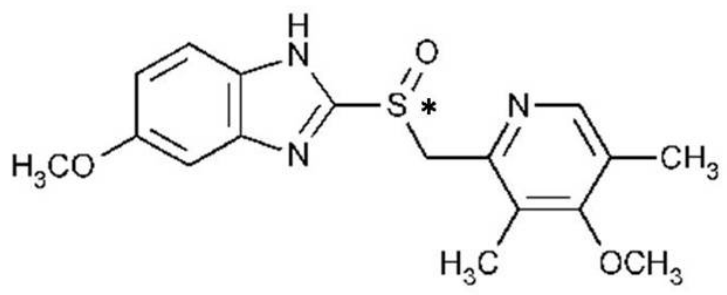

Figure 1. Structure of ( $\mathrm{R}$ and $\mathrm{S}$ ) omeprazole (the atom marked $*$ is the chiral centre).

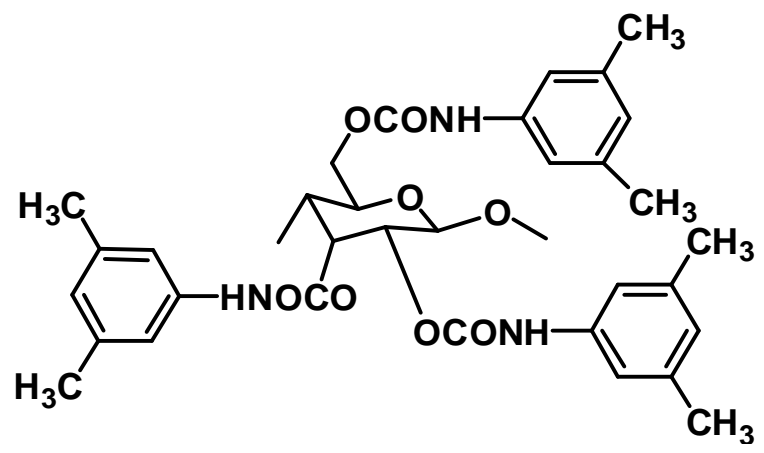

Figure 2. Structure of Chiralcel OD-H (cellulose-tris-3, 5dimethylphenylcarbamate).

\section{MATERIALS AND METHODS}

Chemicals and equipment. The reference standard of omeprazole and esomeprazole were obtained from Incepta Pharmaceuticals Ltd., Savar, Bangladesh. Five commercial samples of omeprazole and esomeprazole were purchased from local market. All solvents methanol, $n$-hexane, 2-propanol, acetic acid and triethylamine were HPLC grade, purchased from Sigma-Aldrich, Germany. Before analysis, reagents were filtered using $0.45 \mu \mathrm{m}$ membrane filter tips. All solutions were prepared by using sonication in ultrasonic bath (Ultrasons Medi-II, Spain).

Method development. To develop a new and easy chiral HPLC method we tried a significant number of methods on trial and error technique using a large number of polar and non-polar solvent 
mixtures as mobile phase with two different chiral

were examined and shown in table 1.

columns, such as Chiralcel OD-H and AGP. Results

Table 1. Trial and error experiment for separation of omeprazole.

\begin{tabular}{|c|c|c|c|c|c|}
\hline $\begin{array}{l}\text { Polar mobile phase/AGP column } \\
\text { Buffer: Organic phase/Others }\end{array}$ & $\begin{array}{l}\text { Elution } \\
\text { order }\end{array}$ & $\begin{array}{l}\text { Retention time } \\
\text { (min) }\end{array}$ & $\begin{array}{l}\text { No. of } \\
\text { theoretical } \\
\text { plates, } \mathrm{N}\end{array}$ & $\begin{array}{l}\text { Tailing } \\
\text { factor, Tf }\end{array}$ & $\begin{array}{l}\text { Resolution, } \\
\text { Rs }\end{array}$ \\
\hline \multirow[t]{2}{*}{$20 \mathrm{mM} \mathrm{NaH}_{2} \mathrm{PO}_{4}(\mathrm{pH} 4.66): \mathrm{ACN}:: 92.5 \%: 7.5 \%$} & $R-S$ & 5.86 & 1076.02 & 0.00 & 0.00 \\
\hline & & 6.93 & 1084.58 & 0.00 & 2.97 \\
\hline \multirow[t]{2}{*}{$20 \mathrm{mM} \mathrm{NaH}{ }_{2} \mathrm{PO}_{4}$ (pH 6.53):ACN::93.5\%:6.5\% } & $R-S$ & 6.37 & 485.95 & 1.22 & 0.00 \\
\hline & & 8.18 & 4207.73 & 1.08 & 2.83 \\
\hline \multirow[t]{2}{*}{$20 \mathrm{mM} \mathrm{NH}_{4} \mathrm{OAc}(\mathrm{pH} 6.78): \mathrm{ACN}:: 90.0 \%: 10.0 \%$} & $R-S$ & 6.51 & 804.80 & 0.09 & 0.00 \\
\hline & & 8.24 & 1046.13 & 1.00 & 1.78 \\
\hline \multirow[t]{2}{*}{$70 \mathrm{mM} \mathrm{NH}_{4} \mathrm{OAc}(\mathrm{pH} \mathrm{6.78):0.1 \%} \mathrm{Acetic} \mathrm{acid}$} & $R-S$ & 12.82 & 813.17 & 1.18 & 0.00 \\
\hline & & 18.39 & 736.27 & 0.93 & 2.47 \\
\hline \multirow[t]{2}{*}{$20 \mathrm{mM} \mathrm{NH}_{4} \mathrm{H}_{2} \mathrm{PO}_{4}: \mathrm{ACN}:: 88 \%: 12 \%$} & $R-S$ & 4.85 & 931.34 & 1.41 & 0.00 \\
\hline & & 6.20 & 817.62 & 1.76 & 1.79 \\
\hline Non-polar mobile phase/OD-H column & $\begin{array}{l}\text { Elution } \\
\text { order }\end{array}$ & $\begin{array}{l}\text { Retention } \\
\text { time }\end{array}$ & $\mathrm{N}$ & Tf & Rs \\
\hline \multirow[t]{2}{*}{ 80:20:0.0\%:0.0\% (Hx: IPA: AA: TEA) } & $S-R$ & 10.33 & 1787.52 & 1.35 & 0.00 \\
\hline & & 12.04 & 1925.3 & 1.34 & 1.45 \\
\hline \multirow[t]{2}{*}{ 80:20:0.0\%:0.2\% (Hx: IPA: AA: TEA) } & $S-R$ & 10.57 & 1863.78 & 1.36 & 0.00 \\
\hline & & 12.51 & 1982.34 & 1.43 & 1.85 \\
\hline \multirow[t]{2}{*}{ 20:80:0.2\%:0.0\% (Hx: IPA: AA: TEA) } & $S-R$ & 4.79 & 1889.34 & 0.00 & 0.00 \\
\hline & & 5.23 & 1686.57 & 0.00 & 1.13 \\
\hline \multirow[t]{2}{*}{ 80:20:0.2\%:0.0\% (Hx: IPA: AA: TEA) } & $S-R$ & 11.51 & 1323.16 & 1.30 & 0.00 \\
\hline & & 13.76 & 1550.03 & 1.40 & 1.69 \\
\hline \multirow[t]{2}{*}{ 20:80:0.2\%:0.2\% (Hx: IPA: AA: TEA) } & $S-R$ & 4.88 & 2468.17 & 1.05 & 0.00 \\
\hline & & 5.40 & 2479.99 & 1.26 & 1.24 \\
\hline \multirow[t]{2}{*}{ 80:20:0.1\%:0.05\% (Hx: IPA: AA: TEA) } & $S-R$ & 9.5 & 1296.44 & 1.51 & 0.00 \\
\hline & & 11.8 & 1407.14 & 1.48 & 1.95 \\
\hline
\end{tabular}

$\mathrm{NaH}_{2} \mathrm{PO}_{4}=$ Sodium di-hydrogen phosphate, $\mathrm{NH}_{4} \mathrm{OAc}=$ Ammonium acetate, $\mathrm{ACN}=$ Acetonitrile $, \mathrm{Hx}=\mathrm{Hexane}, \mathrm{IPA}=\mathrm{Isopropylalcohol}$, $\mathrm{AA}=$ Acetic acid, TEA = Triethylamine.

Chromatographic conditions. SIL 20 series Prominence HPLC (Shimadzu, Japan) equipped with an auto sampler (Model SIL-20 AC), dual pumps (Model 20 AD), column oven (Model CTO-20A), vacuum degasser (Model DGU-20A), UV-visible detector (Model SPD-20A), and LC solution software that runs on Windows was used. The column used had Chiralcel OD-H (cellulose tris-3,5dimethylphenyl carbamate) coated on $5 \mu \mathrm{m}$ silica gel particles $(250 \times 4.6 \mathrm{~mm})$ (Chiral Technologies, Daicel group, West Chester, PA) with guard cartridge $(10 \times 4.0 \mathrm{~mm}, 5 \mu \mathrm{m}$ particle size, Daicel Chemical Industries Ltd., Tokyo, Japan). Chromatographic condition was achieved with $n$-hexane/ 2-propanol/ acetic acid/ triethylamine $(100: 20: 0.2: 0.1, \mathrm{v} / \mathrm{v})$ as mobile phase on Chiralcel OD-H at a flow rate of 1.2 $\mathrm{ml} / \mathrm{min}$ and detected at $300 \mathrm{~nm}$.

Standard solutions. About ten $\mathrm{mg}$ of omeprazole and esomeprazole standard were accurately weighed, transferred into a $100 \mathrm{ml}$ volumetric flask and dissolved in a mixture of $n$-hexane and 2-propanol (1:1) applying sonication in an ultrasonic bath for 15 minutes. The solution was diluted with the solvent mixture up to the mark. The resulting solution had a concentration of $100 \mu \mathrm{g} / \mathrm{ml}$. Dilution of this solution with appropriate volumes of 
the solvent mixture was carried out to obtain solutions of concentrations of $50,60,70,80$, and 90 $\mu \mathrm{g} / \mathrm{ml}$.

Sample solutions of omeprazole and esomeprazole (S- omeprazole). Five commercial omeprazole samples (code A, B, C, D, and E) and esomeprazole samples (code F, G, H, J, and K) were taken. Twenty capsules of each code were weighed and crushed. Capsule powder equivalent to $10 \mathrm{mg}$ of each brand was weighed accurately and transferred to a $100 \mathrm{ml}$ volumetric flask. The content was dissolved with suitable volume of the mixture of n-hexane and 2-propanol (1:1) by sonication for 15 minutes and subsequently more solvent mixture was added into the volumetric flask up to the mark to make the concentration of $100 \mu \mathrm{g} / \mathrm{ml}$. The solution was further diluted two times with the same solvent mixture to obtain the concentration of $50 \mu \mathrm{g} / \mathrm{ml}$ for each code, filtered through $0.45 \mu \mathrm{m}$ membrane filter tips and then injected for analysis.

\section{Method validation}

Specificity. Specificity of a method was determined by testing standard substances against potential interferences. The method was found to be specific because of absences of interference to the test solutions. The optimized chromatograms of omeprazole $(S-$ and $R$ - omeprazole $)$ and esomeprazole ( $S$ - omeprazole) without any interference are shown in figure 3. Single esomeprazole ( $S$ - omeprazole) was injected into HPLC for the detection of $(S)$ - enantiomer in omeprazole.

System suitability. System suitability tests were carried out to verify that the resolution and reproducibility of the chromatographic system are suitable for the analysis to be done. System suitability parameters are reported in table 2.

Solution stability. The solution stability of standards and samples was established under normal bench top conditions, normal storage conditions, and sometimes in the instrument to determine where special storage conditions are necessary or not, for instance, refrigeration or protection from light. A standard solution of concentration of $50 \mu \mathrm{g} / \mathrm{ml}$ was kept in a tightly capped volumetric flask at room temperature $\left(25^{\circ} \mathrm{C}\right)$ on the laboratory bench and at $4^{\circ} \mathrm{C}$ in a refrigerator for 3 days and its stability was tested. The results are given in table 3 .

Linearity and range. Linearity of the method was studied by injecting five solutions with concentrations of omeprazole in the range from 50-90 $\mu \mathrm{g} / \mathrm{mL}$. Each solution was injected three times $(\mathrm{n}=3)$ into HPLC keeping the injection volume constant. The peak areas were plotted against the corresponding concentrations to obtain the calibration curves and linearity data as recorded in table 2 . The calibration curves for (S)- and (R)- enantiomers of omeprazole are shown in figure 4.

Accuracy. Accuracy of the method was examined by recovery experiments which were performed by spiking solutions of known amount of the drug with pre-analyzed sample. The data of the experiments were statistically analyzed using the formula $[\%$ Recovery $=($ Recovered conc. $/$ Injected conc.) $x$ 100] to determine the recovery and the validity of the proposed method. To evaluate the accuracy of the method, successive analysis $(n=3)$ of standard solutions of the drug was carried out and the results are given in table 2 .

Precision repeatability. For validation of the method repeatability was examined by determining the $\%$ RSD $[\%$ RSD = (Standard deviation, SD $/$ Mean) $\times 100$ ] of a single solution of a particular concentration by injecting six times on the same day. The results are presented in table 2 .

Intermediate precision. Intermediate precision was examined by determining the \% RSD for a solution of single concentration by injecting three times on three different days. The results are presented in table 2 .

Detection limit. The limit of detection (LOD) and the limit of quantitation (LOQ) were evaluated from the slope(s) of the calibration curve and the standard deviation (SD) of the peak areas using the following equations: $:^{31}$

$\mathrm{LOD}=(\mathrm{SD} /$ Slope $) \times 3.3$ 
$\mathrm{LOQ}=(\mathrm{SD} / \mathrm{Slope}) \times 10$. The results are shown in table 2.

Robustness. For the HPLC analysis, robustness of the method was demonstrated by changing the variety of chromatographic conditions, like the flow rate and in the wavelength of detection and measuring the \% RSD. For the present study, factors chosen were flow rate $(1.2 \pm 0.2 \mathrm{ml} / \mathrm{min})$ and wavelength ( $300 \pm 2 \mathrm{~nm})$, and $\mathrm{n}=3.0 \% \mathrm{RSD}$ is reported in table 4.

Application of the method. Experiments were conducted to evaluate the presence of equimolar mixture $(1: 1)$ of $(S)$ - and $(R)$ - omeprazole in five commercial samples- A, B, C, D, and E. The recovery was evaluated for - A, B, C, D, E, F, G, H, $\mathrm{J}$, and $\mathrm{K}$. Then the enantiomeric purity of samples- $\mathrm{F}$, $\mathrm{G}, \mathrm{H}, \mathrm{J}$, and $\mathrm{K}$ were calculated by using the formula: ${ }^{35,36}$

Enantiomeric purity $=(\%$ of major enantiomer $\%$ of minor enantiomer).

Enantiomeric purity of commercial samples is shown in table 5 and in figure 5 and typical chromatograms of one marketed formulation for omeprazole and esomeprazole are shown in figures 6 and 7 .

Stability test. In order to evaluate the stability of the method for measuring the active ingredient and its degradation products the drug was exposed to heat, light, acid, base, and oxidizing agent. The drug was then analyzed using the method. Experiments were performed under stress conditions including acid hydrolysis $\left(0.1 \mathrm{~N} \mathrm{HCl}\right.$ at $\left.60^{\circ} \mathrm{C}\right)$, basic hydrolysis $\left(0.1 \mathrm{~N} \mathrm{NaOH}\right.$ at $\left.60^{\circ} \mathrm{C}\right)$, peroxide degradation $(3 \%$ $\mathrm{H}_{2} \mathrm{O}_{2}$ at $\left.60^{\circ} \mathrm{C}\right)$, thermal degradation $\left(60^{\circ} \mathrm{C}\right)$ and photolysis (at $254 \mathrm{~nm})$ for five days $\left(1^{\text {st }}, 3^{\text {rd }}\right.$ and $5^{\text {th }}$ days). Reagents were prepared in methanolic condition for acid, basic and peroxide degradation because the developed chromatography is normal phase chromatography. For thermal and photolysis degradation samples were prepared with a diluent at a concentration of $50 \mu \mathrm{g} / \mathrm{ml}$. The sample solutions for acid, basic and peroxide degradation were prepared by respective reagents with concentration of 50 $\mu \mathrm{g} / \mathrm{ml}$. All the resultant solutions were injected for three times into the system and data were recorded after $1^{\text {st }}, 3^{\text {rd }}$ and $5^{\text {th }}$ days. All the obtained chromatograms are shown in figure 8 and values obtained are reported in table 6 .

Characterization of omeprazole. Microthermal analysis combines the imaging facility of scanning probe microscopy with the ability to characterize, with high spatial resolution, the thermal behavior of materials. This study was performed with thermal methods such as thermo gravimetric analysis (TGA), differential scanning calorimetry (DSC) and scanning electron microscopy (SEM).

Thermo gravimetric analysis (TGA). Thermo gravimetric analysis (TGA) was carried out using TGA analyzer (Model TGA 50, Shimadzu, Japan). The thermal behavior was studied at a heating rate of $20^{\circ} \mathrm{C} / \mathrm{min}$ in the range of $50^{\circ} \mathrm{C}$ to $800^{\circ} \mathrm{C}$ under dinitrogen flow at a rate of $10 \mathrm{~mL} / \mathrm{min}$. A typical chromatogram was shown in figure 9.

Differential scanning calorimetry (DSC). Differential scanning calorimetry (DSC) was carried out by (DSC-60, Shimadzu, Japan) using $2.1 \mathrm{mg}$ samples in a closed aluminum pan at a heating rate of $10^{\circ} \mathrm{C} / \mathrm{min}$ in the range of $30^{\circ} \mathrm{C}$ to $400^{\circ} \mathrm{C}$ under dinitrogen flow at a rate of $20 \mathrm{ml} / \mathrm{min}$. A typical chromatogram was shown in figure 9.

Scanning electron microscopy (SEM). The morphology of the pure racemic omeprazole was characterized by scanning electron microscopy (SEM) (JEOL, JSM-6490LA, USA) with an accelerating voltage set to $20 \mathrm{kV}$. The observed morphology of omeprazole is shown in figure 10 .

\section{RESULTS AND DISCUSSION}

After a number of trials with mobile phases of different composition, n-hexane/ 2-propanol/ acetic acid/ triethylamine $(100: 20: 0.2: 0.1, \mathrm{v} / \mathrm{v})$ was selected as mobile phase because of adequate resolution, efficient theoretical plates number and symmetric peak shape.

Under the optimized chromatographic conditions, the overlaid chromatograms (Figure 3 ) confirm the presence of $(S)$ - and $(R)$ - enantiomers in omeprazole at about $9.65 \pm 0.01 \mathrm{~min}$ and $11.81 \pm$ 
$0.01 \mathrm{~min}$, respectively without any interference. It may be said that the method is specific. System suitability was examined by injecting five replicates of $100 \%$ test concentration of omeprazole into the system. Excellent resolution of 2.36 was obtained.

This method also resulted in symmetric peak shape with tailing 1.24 and 1.23 and good no. of theoretical plates with 2345 and 2275 for $(S)$ - and $(R)$ - omeprazole, respectively. It showed insignificant deviation in the values of relative retention $(\mathrm{k} 1$ and k2), selectivity ( $\alpha$ ), resolution (Rs) and no. of theoretical plates $(\mathrm{N})$. The calibration curve for $(S)$ and $(R)$ - omeprazole constructed from chromatograms of omeprazole solutions of concentrations over the range of 50 to $90 \mu \mathrm{g} / \mathrm{ml}$ shows linearity with coefficient of determination $\left(\mathrm{r}^{2}\right)$ values of 0.999 and 0.998 , respectively which were found in the limit $\left(r^{2}>0.995\right)$ indicating good linearity of calibration curve. The linearity curves are shown in figure 4 and the parameters are given in table 2 .

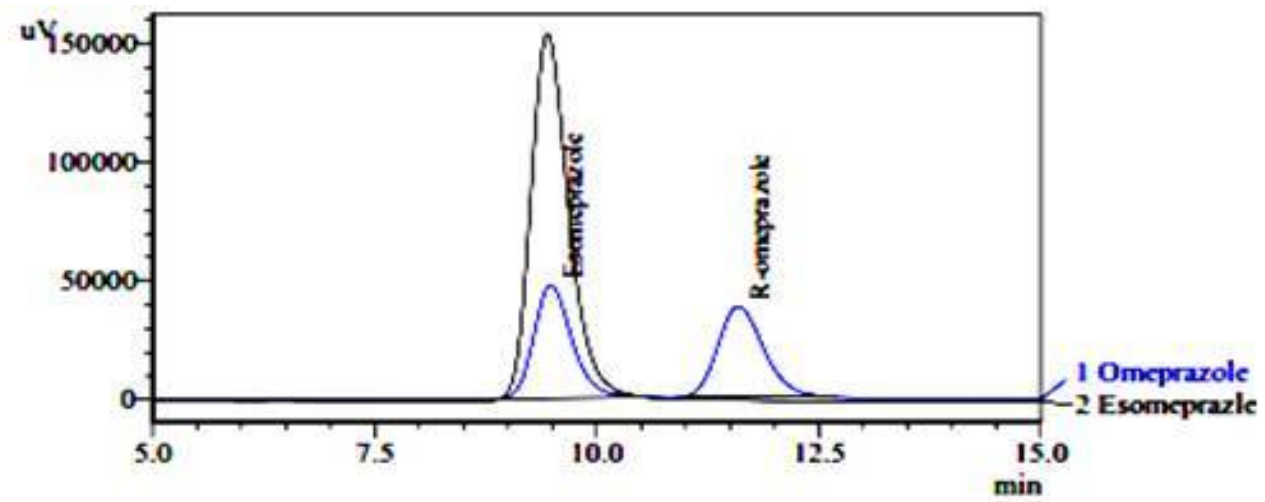

Figure 3. Overlaid chromatograms of esomeprazole, ( $S$ - omeprazole) and omeprazole, ( $R S$ - omeprazole).

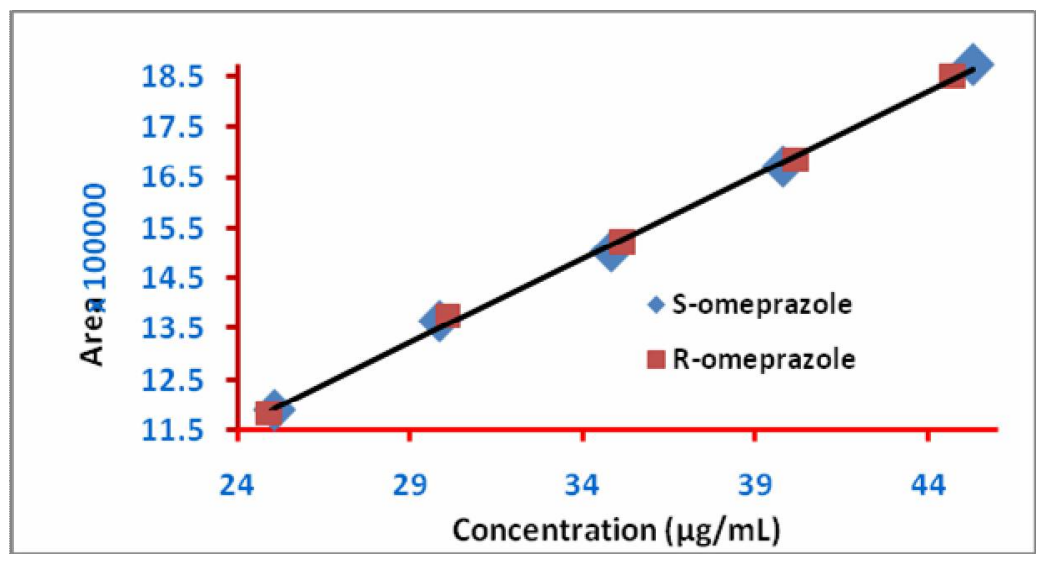

Figure 4. Linearity of calibration curves, (A) $S$ - omeprazole, and (B) $R$ - omeprazole.

The limits of detection (LOD) were found to be $0.71 \mu \mathrm{g} / \mathrm{ml}$ and $2.16 \mu \mathrm{g} / \mathrm{ml}$ for $(S)$ - and $(R)$ omeprazole, respectively. The limit of quantitation (LOQ) were $1.16 \mu \mathrm{g} / \mathrm{ml}$ and $3.51 \mu \mathrm{g} / \mathrm{ml}$ for $(S)$ - and $(R)$ - omeprazole, respectively. The average percentage of recovery was calculated and it was found to be $100.85 \%$ to $101.36 \%$ for $(S)$ - and
$99.81 \%$ to $101.62 \%$ for $(R)$ - omeprazole against the concentration of 65,75 , and $85 \mu \mathrm{g} / \mathrm{ml}$, respectively. The proposed method was found to be precise and reproducible with \% RSD of $0.05 \%$ and $0.19 \%$ for $(S)$ - and $0.03 \%$ and $0.13 \%$ for $(R)$ - omeprazole, respectively. All the validation parameters are shown in table 2. 
Solution stability study was carried out to calculate \% RSD of area for three consecutive days at $25^{\circ} \mathrm{C}$ and $4{ }^{\circ} \mathrm{C}$. At $25^{\circ} \mathrm{C}$ the value of $\%$ RSD was found to be $0.06 \%$ and $0.09 \%$ for $(S)$ - and $(R)$ omeprazole. At $4{ }^{\circ} \mathrm{C}$ the value of $\%$ RSD was $0.10 \%$ and $0.15 \%$ for $(S)$ - and $(R)$ - omeprazole, respectively which demonstrated that the drug was fairly stable at normal and freezing temperatures. The data are represented in table 3 .

The method was found to be robust after changing the conditions like detection wavelength $( \pm 2 \mathrm{~nm})$ and flow rate $( \pm 0.2 \mathrm{ml} / \mathrm{min})$. \% RSD was calculated for each variation. Values obtained are given in table 4.

Table 2. Results of method validation parameters.

\begin{tabular}{lll}
\hline Parameters & $(S)$ - omeprazole & $(R)$ - omeprazole \\
\hline Linear equation & $\mathrm{y}=40252 \mathrm{x}+29041$ & $\mathrm{y}=40010 \mathrm{x}+32889$ \\
Coefficient of determination $(\mathrm{r} 2>0.995)$ & 0.999 & 0.998 \\
Linearity range & & $50-90 \mu \mathrm{g} / \mathrm{ml}$ \\
Resolution $(\geq 2)(\mathrm{n}=5)$ & 2.36 & \\
Theoretical plates $(\geq 2000)(\mathrm{n}=5)$ & 2345 & 2275 \\
Tailing factor $(\leq 2)(\mathrm{n}=5)$ & 1.24 & 1.23 \\
Relative retention $(\mathrm{k} 1$ and $\mathrm{k} 2)(\mathrm{n}=5)$ & 2.33 & 3.10 \\
Selectivity $(\alpha)(\mathrm{n}=5)$ & & \\
Precision $($ intra-day, $\mathrm{n}=6)(\% \mathrm{RSD} \leq 2)$ & $0.05 \%$ & $0.03 \%$ \\
Precision $($ inter-day, $\mathrm{n}=6)(\% \mathrm{RSD} \leq 2)$ & $0.19 \%$ & $0.13 \%$ \\
Accuracy $(\mathrm{n}=3)(\mathrm{avg} . \%$ recovery $)$ & & \\
Standard+spike $(\mu \mathrm{g} / \mathrm{mL})$ & & \\
$(55+10)$ & $101.07 \%$ & $99.81 \%$ \\
$(65+10)$ & $101.36 \%$ & $101.62 \%$ \\
$(75+10)$ & $100.85 \%$ & $101.13 \%$ \\
LOD $(\mu \mathrm{g} / \mathrm{mL})$ & 0.71 & 2.16 \\
LOQ $(\mu \mathrm{g} / \mathrm{mL})$ & 1.16 & 3.51 \\
\hline $\mathrm{n}=\mathrm{number}$ of determinations & &
\end{tabular}

Table 3. Results of solution stability.

\begin{tabular}{lcccc}
\hline Day & \multicolumn{3}{c}{ At $25{ }^{\circ} \mathrm{C}$} & \multicolumn{2}{c}{ At $4{ }^{\circ} \mathrm{C}$} \\
\hline Day 1 & $\begin{array}{c}(\mathrm{S}) \text { - omeprazole } \\
(\mathrm{n}=3)(\% \text { RSD })\end{array}$ & $\begin{array}{c}(\mathrm{R}) \text { - omeprazole } \\
(\mathrm{n}=3)(\% \mathrm{RSD})\end{array}$ & $\begin{array}{c}(\mathrm{S}) \text { - omeprazole } \\
(\mathrm{n}=3)(\% \text { RSD })\end{array}$ & $\begin{array}{c}(\mathrm{R}) \text { - omeprazole } \\
(\mathrm{n}=3)(\% \mathrm{RSD})\end{array}$ \\
Day 2 & $0.05 \%$ & $0.09 \%$ & $0.08 \%$ & $0.15 \%$ \\
Day 3 & $0.10 \%$ & $0.06 \%$ & $0.13 \%$ & $0.18 \%$ \\
Avg. & $0.04 \%$ & $0.12 \%$ & $0.10 \%$ & $0.13 \%$ \\
\hline
\end{tabular}

$\mathrm{n}=$ number of determinations.

This analytical method was applied to quantitate the content of $(S)$ - and $(R)$ - omeprazole in omeprazole samples - A, B, C, D, and E and as well as to calculate the $\%$ purity of esomeprazole samples$\mathrm{F}, \mathrm{G}, \mathrm{H}, \mathrm{J}$, and $\mathrm{K}$. The average content of $(S)$ omeprazole was found to vary from $49.14 \%$ to
$51.50 \%$ while the content of $(R)$ - omeprazole varied from $48.50 \%$ to $50.86 \%$ in the formulations- A, B, C, D and E. \% RSD of samples- A, B, C, D and E were less than $2.0 \%$ for both enantiomers. The data are shown in figure 5. For esomeprazole samples- F, G, $\mathrm{H}$, J, and $\mathrm{K}$ average content of $(S)$ - omeprazole varied 
from $99.94 \%$ to $100.00 \%$ whereas the average content of $(R)$ - omeprazole found as impurity varied from $0.06 \%$ to $0.22 \%$. The percent enantiomeric excess (\% ee) of samples- F, G, H, J, and $\mathrm{K}$ were determined. The results are recorded in table 5 . Typical chromatograms of both omeprazole and esomeprazole samples are shown in figures 6 and 7.

Table 4. Robustness study.

\begin{tabular}{lllll}
\hline Change in flow rate $(\mathrm{mL} / \mathrm{min})$ & $\begin{array}{l}\text { Average Rt of }(\mathrm{S})- \\
\text { omeprazole } \pm \mathrm{SD}\end{array}$ & $\begin{array}{l}\text { Average Rt of (R)- } \\
\text { omeprazole } \pm \mathrm{SD}\end{array}$ & $\begin{array}{l}\text { \% RSD of (S)- } \\
\text { omeprazole }\end{array}$ & $\begin{array}{l}\text { \% RSD of (R)- } \\
\text { omeprazole }\end{array}$ \\
\hline 1.4 & $7.87 \pm 0.05$ & $9.76 \pm 0.01$ & $0.13 \%$ & $0.06 \%$ \\
1.2 & $9.65 \pm 0.01$ & $11.81 \pm 0.01$ & $0.06 \%$ & $0.05 \%$ \\
1.0 & $11.71 \pm 0.01$ & $13.91 \pm 0.01$ & $0.01 \%$ & $0.04 \%$ \\
Change in wavelength $(\mathrm{nm})$ & $\begin{array}{l}\text { Average Rt of (S)- } \\
\text { omeprazole } \pm \text { SD }\end{array}$ & $\begin{array}{l}\text { Average Rt of (R)- } \\
\text { omeprazole } \pm \text { SD }\end{array}$ & $\begin{array}{l}\% \text { RSD of (S)- } \\
\text { omeprazole }\end{array}$ & $\begin{array}{l}\text { \% RSD of (R)- } \\
\text { omeprazole }\end{array}$ \\
300 & $1144101 \pm 343.42$ & $1142985 \pm 321.27$ & $0.03 \%$ & $0.03 \%$ \\
302 & $1043720 \pm 381.24$ & $1043849 \pm 736.58$ & $0.04 \%$ & $0.07 \%$ \\
\hline
\end{tabular}

$\mathrm{n}=3$; where, $\mathrm{n}=$ number of determinations.

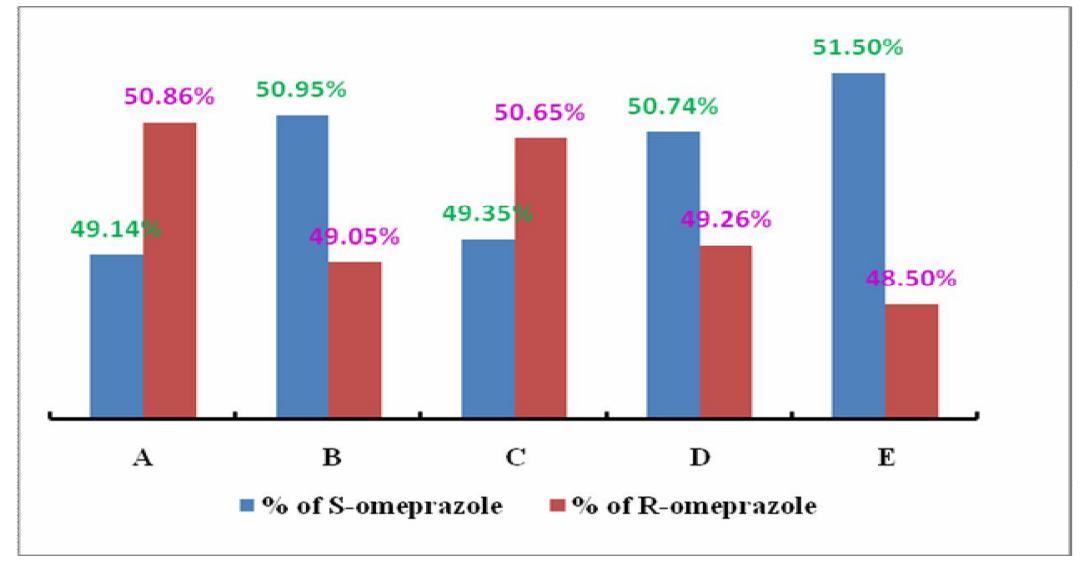

Figure 5. The content of $(S)$ - and $(R)$ - omeprazole in commercial racemic omeprazole.

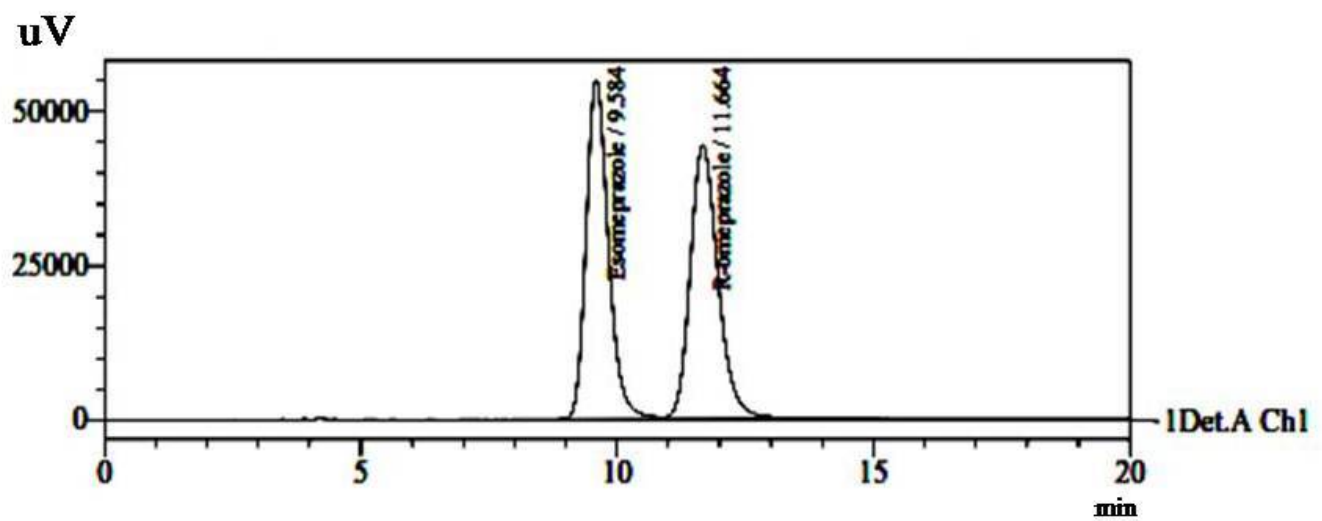

Figure 6. Typical chromatogram of an omeprazole sample. 


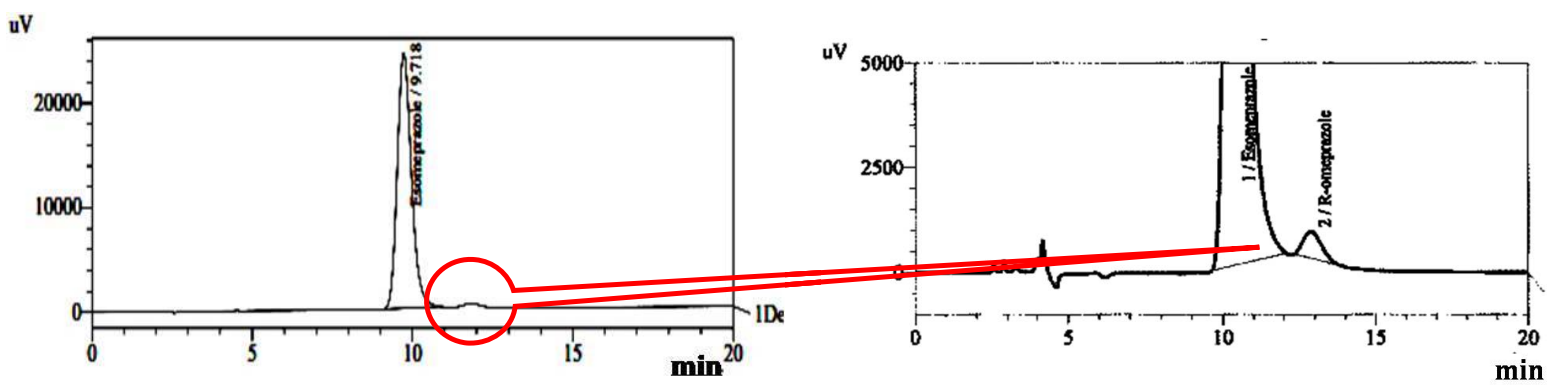

Figure 7. Typical chromatogram of an esomeprazole sample (sample J) containing impurity of $(R)$-omeprazole.

Table 5. Purity of esomeprazole market samples.

\begin{tabular}{lccc}
\hline Identity of Samples & content of S-omeprazole & R-omeprazole as impurity & purity of S-omeprazole \\
\hline F & $99.94 \%$ & $0.06 \%$ & $99.88 \%$ \\
G & $100.00 \%$ & $0.00 \%$ & $100.00 \%$ \\
H & $100.00 \%$ & $0.00 \%$ & $100.00 \%$ \\
J & $99.77 \%$ & $0.22 \%$ & $99.55 \%$ \\
K & $100.00 \%$ & $0.00 \%$ & $100.00 \%$ \\
\hline
\end{tabular}

$\mathrm{n}=3$; where, $\mathrm{n}=$ number of determinations.

Table 6. Summary of stress degradation study $(n=3)$.

\begin{tabular}{|c|c|c|c|c|c|c|}
\hline \multirow{2}{*}{$\begin{array}{l}\text { Degradation } \\
\text { parameters at } \\
60^{\circ} \mathrm{C}\end{array}$} & \multicolumn{2}{|c|}{ Day 1} & \multicolumn{2}{|c|}{ Day 2} & \multicolumn{2}{|c|}{ Day 3} \\
\hline & $\begin{array}{l}\text { \% Deg. of (S)- } \\
\text { omeprazole }\end{array}$ & $\begin{array}{c}\text { \% Deg. of (R)- } \\
\text { omeprazole }\end{array}$ & $\begin{array}{c}\text { \% Deg. of (S) } \\
\text { omeprazole }\end{array}$ & $\begin{array}{c}\text { \% Deg. of (R)- } \\
\text { omeprazole }\end{array}$ & $\begin{array}{l}\text { \% Deg. of (S)- } \\
\text { omeprazole }\end{array}$ & $\begin{array}{c}\% \text { Deg. of (R)- } \\
\text { omeprazole }\end{array}$ \\
\hline Acidic & $\mathrm{cd}^{*}$ & $\mathrm{~cd}$ & $\mathrm{~cd}$ & $\mathrm{~cd}$ & $\mathrm{~cd}$ & $\mathrm{~cd}$ \\
\hline Basic & $0.18 \%$ & $0.10 \%$ & $0.70 \%$ & $0.27 \%$ & $0.84 \%$ & $0.53 \%$ \\
\hline Peroxide & cd & $\mathrm{cd}$ & $\mathrm{cd}$ & $\mathrm{cd}$ & $\mathrm{cd}$ & $\mathrm{cd}$ \\
\hline Thermal & $0.19 \%$ & $0.18 \%$ & $0.52 \%$ & $0.29 \%$ & $0.77 \%$ & $0.90 \%$ \\
\hline Photolysis & $\mathrm{cd}$ & $\mathrm{cd}$ & $\mathrm{cd}$ & $\mathrm{cd}$ & $\mathrm{cd}$ & $\mathrm{cd}$ \\
\hline
\end{tabular}

$\mathrm{n}=$ number of determinations, $* \mathrm{~cd}=$ complete degradation, $\% \mathrm{deg} .=$ percentage of degradation.

Applying this proposed method forced degradation study was carried out for five days. The drug was exposed to acid, alkali, oxidative, photolysis and thermal stress conditions. Here, sample solutions were analyzed by the validated method after $1^{\text {st }}, 3^{\text {rd }}$ and $5^{\text {th }}$ days. In acid hydrolysis, photolysis and oxidation, it was observed that the drug was completely degraded and in basic hydrolysis and thermal condition it remained almost stable. It is well established that PPIs are formulated as enteric-coated as they are unstable in acid media and show greater stability in basic media.$^{37,38}$ The chromatograms for all stress conditions are shown in figure 8 and the derived parameters in table 6 .

Microthermal analysis was also carried out to observe the morphology and thermal behavior of the racemic omeprazole. TGA was carried out in the range of $50^{\circ} \mathrm{C}$ to $800^{\circ} \mathrm{C}$ and it was observed that the drug is stable at $60^{\circ} \mathrm{C}$ with the stability of $99.95 \%$ (Figure 9) and significant degradation starts at $171.0^{\circ} \mathrm{C}$. In DSC experiments the melting of the drug was observed at $155.63^{\circ} \mathrm{C}$ (Figure 9). ${ }^{39}$ Morphological behavior was also performed for racemic omeprazole and also for treated omeprazole (at $60^{\circ} \mathrm{C}$ for 5 days) with SEM and the same 
characteristic behavior (figure 10) was observed. In forced degradation study of omeprazole, it was found to be almost stable in thermal stress condition which was shown above in Figure 7(C). The combination of

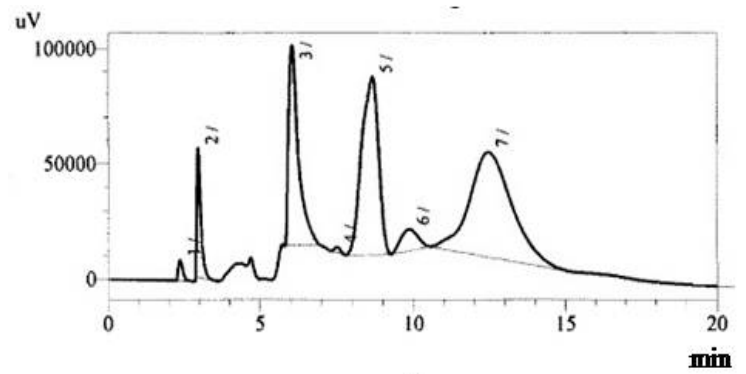

A
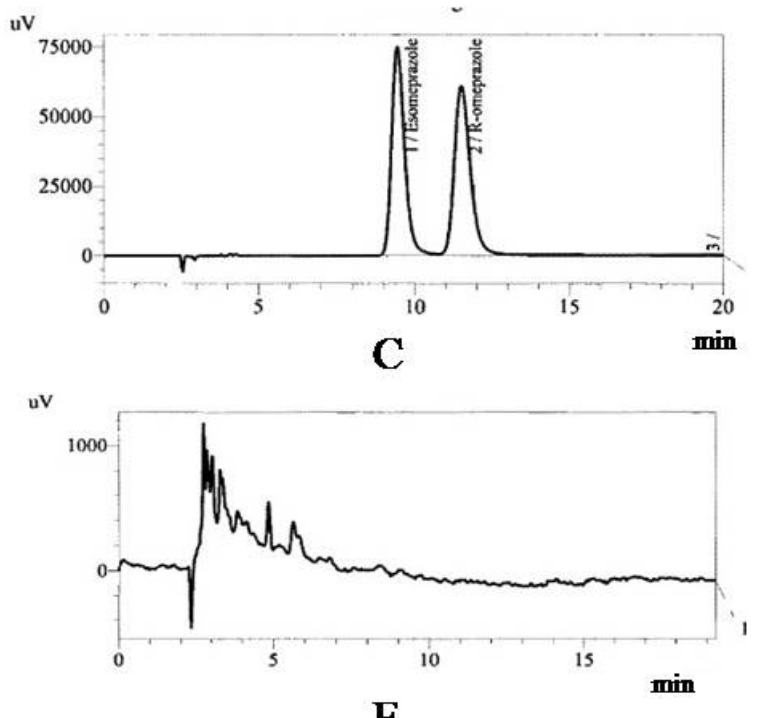

uv

$\mathbf{E}$

Figure 8. Chromatograms of stressed conditions: (A) acid hydrolysis, (B) oxidation, (C) thermal degradation, (D) basic hydrolysis, and (E) photolysis.

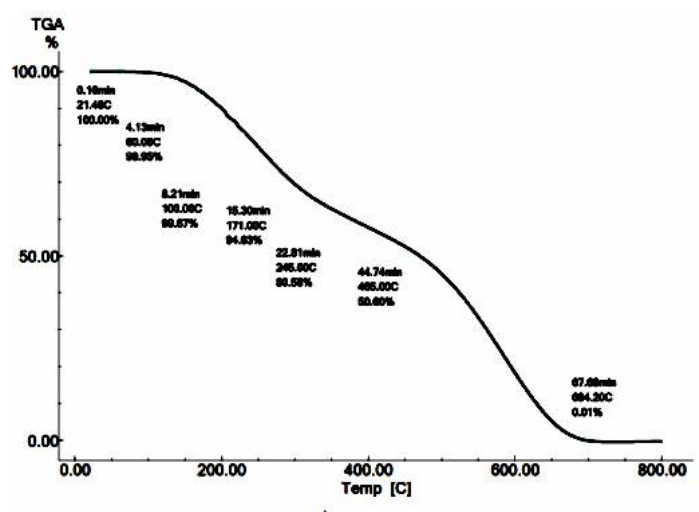

A

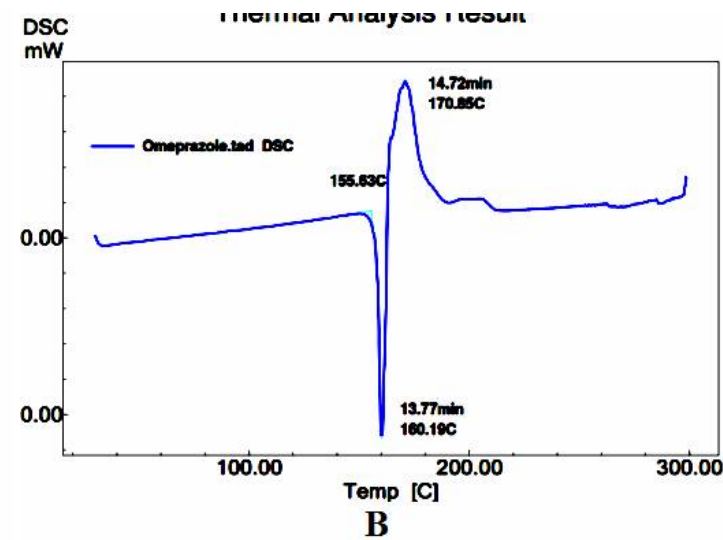

Figure 9. (A) TGA of reference omeprazole, (B) DSC of reference omeprazole. the scanning electron microscopy and thermal analysis opens new areas for the study of a material's properties at a very small scale.
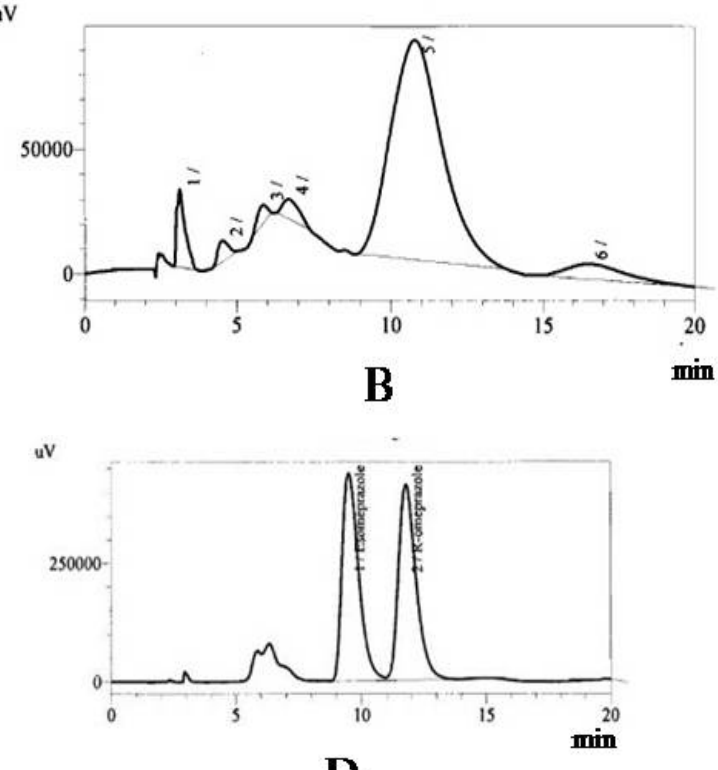

D 


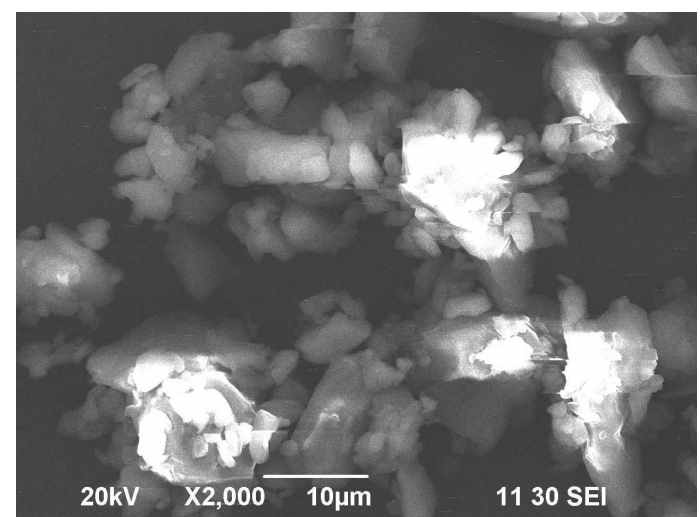

A

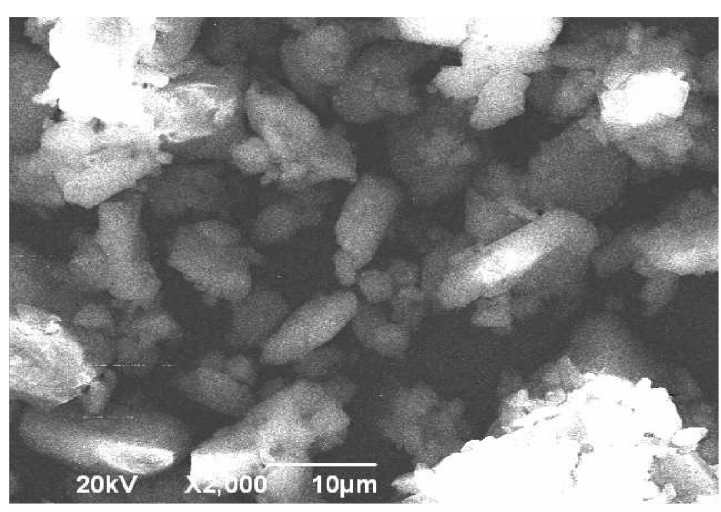

B

Figure 10. (A) SEM image of omeprazole (control), (B) SEM image of omeprazole at $60^{\circ} \mathrm{C}$ after 5 day.

\section{CONCLUSION}

The proposed method for enantiomeric separation and quantitative determination of omeprazole enantiomers in tablets, capsules and bulk drugs is efficient and sensitive. In the analysis the excipients of the commercial samples did not interfere, which proved the enantio-specificity of the method. The main advantage is that a single chromatographic run allows the identification of the $(S)$ - and $(R)$ - enantiomers in a short time for both (approximately within $12 \mathrm{~min}$ ) and permits the analyst to analyze large no. of samples within a short period of time. Thus, the method was found to be simple, accurate, precise, and less time consuming with improved resolution compared to reported methods. So, the established method can be successfully applied for the routine analysis of omeprazole enantiomers in pharmaceutical formulations.

\section{ACKNOWLEDGEMENTS}

The authors extend their gratitude to Incepta Pharmaceuticals Ltd., Savar, Bangladesh for providing reference samples.

\section{CONFLICTS OF INTERESTS}

The authors declare that there is no conflict of interests regarding the publication of this paper.

\section{REFERENCES}

1. Horn, J. 2000. The proton-pump inhibitors: similarities and differences. Clin. Ther. 22, 266-280.

2. De Vault, K.R. and Castell, DO. 2004. Updated guidelines for the diagnosis and treatment of gastroesophageal reflux disease. Am. J. Gastroenterol. 94, 1434-1442.

3. Sauchs, G. 1997. Proton pump inhibitors and acid related diseases. Pharmacotherapy. 17, 22-37.

4. Vyas, S., Patel, A., Ladva, K.D., Joshi, H.S. and Bapodra, A.H. 2011. Development and validation of a stability indicating method for the enantioselective estimation of omeprazole enantiomers in the enteric-coated formulations by high-performance liquid chromatography. J. Pharm. Bioallied. Sci. 3, 310-314.

5. https://en.wikipedia.org/wiki/Omeprazole (Date of access June 8, 2017).

6. Shin, J.M., Munson, K., Vagin, O. and Sachs, G. 2009. The gastric HK-ATPase: Structure, function, and inhibition. Pflugers Arch. 457, 609-622.

7. Sachs, G., Shin, J.M., Vagin, O., Lambrecht, N., Yakubov, I. and Munson, K. 2000. The gastric H, KAT Pase as a drug target. J. Clin. Gastroenterol. 41, 226-242.

8. Rohss, K., Hasselgren, G. and Hedenstrom, H. 2002. Effect of esomeprazole $40 \mathrm{mg}$ vs omeprazole $40 \mathrm{mg}$ on 24-hour intragastric $\mathrm{pH}$ in patients with symptoms of gastroesophageal reflux disease. Dig. Dis. Sci. 47, 954-958.

9. Anderson, T., Hassan-Alin, M., Hasselgren, G., Rohss, K. and Weidolf, L. 2001. Pharmacokinetic studies with esomeprazole, the $(S)$-isomer of omeprazole. Clin Pharmacokinet. 40, 411-426.

10. Maier, N.M., Franco, P. and Linder, W. 2001. Separation of enantiomers: needs challenges, perspectives. J. Chromatogr. A. 906, 3-33. 
11. Nguyen, LA., Hua, H. and Pham-Huy, C. 2006. Chiral drugs: An overview. Int. J. Biomed. Sci. 2, 85-100.

12. Anil, K.S., Erika, R.M., Kedor, H. and Maria, I.R.M. Santoro. 2004. Enantiomeric separation and quantitative determination of propranolol enantiomers in pharmaceutical preprarations by chiral liquid chromatography. Braz. J. Pharm. Sci. 40, 301-308.

13. Kim, M., Kyung, S.Y., Truong, Q., Mai, X., Chung, H., Kang, J. and Kim, K.H. 2017. Determination of rabeprazole enantiomers in commercial tablets using immobilized cellulose-based stationary phase. Arch. Pharm. Res. 40, 373381.

14. Levin, S. and Abu-Lafi, S.1993. The role of enantioselective liquid chromatographic separation using chiral stationary phases in pharmaceutical analysis. Adv. Chromatogr. 33, 233.

15. Cirilli, R., Ferretti, R., Gallinella, B., Santis, E.D., Zanitti, I. and Torre, F.L. 2008. High-performance liquid chromatography enantioseparation of proton pump inhibitors using the immobilized amylase-based Chiralpak IA chiral stationary phase in normal-phase, polar organic and raversed-phase conditions. . J. Chromatogr. A. 1177, 105113.

16. Stenhoff, H., Blomqvist, A. and Lagerstrom, P.O. 1999. Determination of the enantiomers of omeprazole in blood plasma by normal phase liquid chromatography and detection by atmospheric pressure ionization tandem mass spectrometry. J. Chromatogr. B. Biomed. Sci. Appl. 734, 191-201.

17. Yoshida, T., Kito, M., Tsujii, M. and Nagasawa, T. 2001. Microbial synthesis of a proton pump inhibitor by enantioselective oxidation of a sulfide into its corresponding sulfoxide by cunninghamella echinulata MK 40. Biotech. Left. 23, 1217-1222.

18. Allenmark, S., Bomgren, B., Boren, H. and Lagerstrom, P.O. 1984. Direct optical resolution of a series of pharmacologically active racemic sulfoxide by highperformance liquid affinity chromatography. Anal. Biochem. 136, 293-297.

19. Erlandsson, P., Isaksson, R., Lorentzon, P. and Lindberg, P. 1990. Resolution of the enantiomers of omeprazole and some of its analogues by liquid chromatography on a trisphenylcarbamoylcellulose-based stationary phase: the effect of the enantiomers of omeprazole on gastric glands. $J$. Chromatogr. A. 532, 305-319.

20. Toribio, L., Del Nozal, M.J., Bernal, J.I., Alonso, C. and Jimenze, J.J. 2005. Comparative study of the enantioselective separation of several antiulcer drugs by high-performance liquid chromatography and supercritical fluid chromatography. J. Chromatogr. A. 1091. 118-123.
21. Balmer, K., Persson, B.A. and Lagerstrom, P.O. 1994. Stereoselective effects in the separation of enantiomers of omeprazole and other substituted benzimidazoles on different chiral stationary phase. J. Chromatogr. A . 660, 269-273.

22. Miura, M., Kagaya, H., Tada, H., Uno, T., Yasui-Furukori, N., Tateishi, T. and Suzuki, T. 2006. Enantioselective disposition of rabeprazole in relation to CYP2C19 genotypes. Br. J. Clin. Pharm. 61, 315-320.

23. Wainer, I.W., Stiffin, R.M. and Shibata, T. 1987. Resolution of enantiomeric aromatic alcohols on a cellulose tribenzoate high-performance liquid chromatography chiral stationary phase: A proposed chiral recognition mechanism. $J$. Chromatogr. A. 441, 139-151

24. Kirkland, K.M. 1995. Optimization of chiral selectivity on cellulose-based high-performance liquid chromatographic columns usihg aprotic mobile-phase modifiers. $J$. Chromatogr. A. 718, 9-26.

25. Mehta, A.C. 1998. Direct separation of drug enantiomers by high-performance liquid chromatography with chiral stationary phases. J. Chromatogr. A. 426, 1-13.

26. Andersson, M.E., Aslam, D., Clarke, A. and Roeraade, H. 2003. Evaluation of generic chiral liquid chromatography screens for pharmaceutical analysis. J. Chromatogr. A. 1005, 83-101.

27. Matthijs, N., Perrin, C., Maftouh, M., Massart, D.L. and Vander, H.Y. 2004. Definition and system implementation of strategies for method development of chiral separations in normal- or reversed-phase liquid chromatography using polysaccharide based stationary phases. J. Chromatogr. A. 1041, 119-133.

28. Sanchez, F.G., Diaz, A.N. and Pareja, A.G. 1996. HPLC determination of tryptophan enantiomers with photometric, fluorimetric and diode laser polarimetric detection. Chromatographia. 42, 494-498.

29. USP 32-NF 27, General Chapter 1225-1226, Validation of Compendial Methods, 2009.

30. USP 32-NF 27, General Chapter 1058, Analytical Instrument Quantification, 2009.

31. International Conference on Harmonisation (ICH), validation of analytical procedures: Text and Methodology Q2 (R1) in November 2005.

32. Price, D.M., Reading, M. and Trevor, J.L. 1999. Application of micro-thermal analysis. J. Therm. Anal. Calorim. 56, 673679.

33. Moon, I., Androsch, R., Chen, W. and Wunderlich, B. 2000. The principles of micro-thermal analysis and its application to the study of macromolecules. J. Therm. Anal. Calorim. 59, 187-203. 
34. Craig, D.Q.M., Kett, V., Andrews, C.S. and Royall, P.G. 2002. Pharmaceutical applications of micro-thermal analysis. J. Pharm. Sci. 91, 1201-1213.

35. Francis A. Carey and Richard J. Sundberg Kluar, Advanced organic chemistry Part A: Structure and Mechanism, plenum publishers. $5^{\text {th }}$ edition, Chapter 2, 2007.

36. http://web.chem.ucla.edu/ harding/IGOC/E/enantiomeric_ex cess.html (Date of access May 22, 2017).
37. Koda-Kimble M.A: Handbook of applied therapeutics, Williams and Wilkins. $8^{\text {th }}$ edition, Chapter 26, 2007.

38. Storpirtis, S. and Rodrigues, D. 1998. In vitro evaluation of dissolution properties and degradation products of omeprazole in enteric-coated pellets. Drug. Dev. Ind. Pharm. 24, 1101-1107.

39. Mammucari, R. and Foster, N.R. 2008. Dense gas technology and cyclodextrins: State of the art and potential. Curr. Org. Chem. 12, 476-491. 